\title{
Die vakwetenskaplike en wysgerige betekenis van Stoker se konfrontasie met die 'moderne desendensieleer'
}

\author{
D.F.M. Strauss \\ Departement Wysbegeerte \\ Universiteit van die Oranje-Vrystaat \\ BLOEMFONTEIN
}

\begin{abstract}
In 1926 Stoker wrote an article dealing with the modern biological theory of descent. This contribution endeavours 10 investigate those arguments and insights which are still valid today.

With reference to Von Uexkill Stoker first of all correcily emphasizes that the Danwinistic theory of descent does not belong within the domain of biology as a special science - it is nothing but a part of philosophy that should be treated within a philosophy of nature. In various contexts Stoker also points out that similarities also presuppose differences - something consistently overlooked by Danwinism.

The shoricomings in the 'biogenelic basic law' of Hacckel - which claims that ontogenesis is a recapitulation of phylogenesis -- as well as of the neglected issue of constancy are liffed out. Stoker in fact advances a remarkably balanced perspective on the relationship between constancy and dynamics.
\end{abstract}

\section{Inleiding}

Stoker is 'n wysgeer wat geseënd was met 'n uitsonderlike lang en vrugbare akademiese loopbaan - en wat daarbenewens die voorreg van 'n lang en produktiewe emeritaat beleef het. Die enkele kere wat ek die voorreg gehad het on na 'n voordrag van hoin te luister, het dit my altyd opgeval dat hy ' $n$ buitengewone analitiese vernuf en skerpsimnigheid besit. Dit blyk ook uit die uitgebreidheid en wydstrekkende wiekslag van sy publikasies sedert die jare twintig. Telkens omlyn hy 'n tema wat hy wil behandel deur dit onderskeidend af te grens van dit wat buite die gesigsveld van sy behandelingsplan val. As demonstrasie van sowel die wetenskaplike deeglikheid en belyndheid as van die wetenskaplike beskei- 
denheid en openheid waarmee Stoker te werk gaan, skenk hierdie artikel aandag aan sy bydrae uit die jaar 1926 oor die moderne 'desendensieleer'.

\section{Stoker oor die moderne afstammingsleer}

Die eerste opvallende eienskap van hierdie artikel is geleë in die biologiese vakliteratuur wat Stoker bstudeer het. W. Berndt, Fr. Bosch, Hans Driesch, F.J. Buijtendijck en Jakob von Uexküll is almal prominente biologiese outeurs uit die eerste twee dekades van hierdie eeu. Natuurlik figureer Darwin en Häckel, asook H. Bavinck en A. Kuyper in hierdie vakliteratuur. Kolfhaus (1901) se Duitse vertaling van Kuyper se beroemde rede uit die jaar 1900 handel ook oor evolusionisme (Evolutionismus: das Dogma moderner Wissenschaft).

Tot my eie verbasing tref ons heel terloops later in hierdie artikel ' $n$ opmerking aan wat verwys na Goethe maar wat ewe goed in die jare sewentig of tagtig van hierdie eeu geformuleer kon gewees het deur een of ander prominente figuur in die nuwere wetenskapsteorie. Dit is vandag sekerlik nie vreemd om te verneem dat daar in die wetenskap nie feite an sich bestaan nie, aangesien feite sogenaamde reeds teorie-'gelaai' (of: 'gekleurd') is. Stoker (1926:61) wys daarop dat die bewyse ten gunste van die 'desendensieteorie' inherent reeds evolusionisties is: "en dis nie die kritiek op die teorieë, maar die kritiek op die bewyse daarvoor, wat in die moderne biologie teleurstelling en langsame wantroue begin wakker roep". Hierdie opmerking word voorafgegaan deur die volgende merkwaardige uitspraak: "Goethe het al gesê dat in die sogenaamde 'feite' meestal baie meer teorie sit, as wat gewoonlik erken word" (Stoker, 1926:61).

Wie egter die artikel van Stoker met die volgende verwagting lees, word aangenaam verras: watter argumente en insigte $\mathrm{kom}$ in hierdie artikel na vore wat vandag nog steeds as houdbaar en sinvol beskou kan word?

Stoker haal vroeg in sy uiteensetting die treffende woorde van Jacob von Uexküll (met sy Umwelltehre is hy die vader van die moderne ekologie) aan waar hy daarop wys dat die Darwinisme meer 'n geloof as ' $n$ wetenskap is. ${ }^{1}$ Stoker wys daarop dat vername bioloë teen 1926 veel versigtiger oor die afstammingsprobleem praat as enkele dekades tevore. Party van hulle besef selfs duidelik "dat die hele desendensie-teorie nie eintlik in die streng wetenskaplike biologie tuishoort nie, maar 'n stuk filosofie is en in die natuurfilosofie behandel moet word" (Stoker, 1926:19). Hierdie insig is nie alleen uiters fundamenteel nie, maar dit hou nog steeds stand - ook vandag is dit die belangrikste insig wat by aan-

1 "Der Darwinismus, ... ist mehr eine Religion als cine Wissenschaft", Suhrkamp-uitgawe (1973) van dic 1928-druk. p. 290. Stokcr haal aan uit dic 1920-uitgawe, p. 191. 
hangers van die 'desendensieleer' ontbreek, naamlik dat hulle eintlik voorstanders is van 'n wysgerige teorie wat hoegenaamd nie op 'n suiwer vakwetenskaplike status aanspraak kan maak nie.

Die tweede gesigspunt wat Stoker na vore bring - en wat vandag nog ewe waar is - is gegee in die onmoontlikheid om van die evolusieleer te praat. Stoker (1926: $19)$ stel dit só: "al wat bestaan is ' $n$ hele serie van verskillende desendensie-teorieë".

Nadat Stoker vervolgens aandag geskenk het aan die probleem van ' $n$ éen- of véélstam-teorie ('n monofiletiese teenoor 'n polifiletiese desendensieleer), skenk hy aandag aan bewyse uit gebiede soos die oorerwingswetenskappe, die biologiese sistematiek, vergelykende morfologie, vergelykende anatomie, serologie, embriologie, rudimentêre organe, asook bewyse uit die dieregeografie en vergelykende biologie (Stoker, 1926:22 e.v.; 30 e.v.; 44 e.v.).

Ten opsigte van die mutasieleer wys Stoker (1926:27) daarop dat "alle bekende mutasies en die inutasieleer nie bo alle twyfel verhewe is" nie. ${ }^{2}$ Met instemming haal Stoker Schwerschlager en Berndt aan wat selfs beweer dat "ons geen werklik doelmatig-gerigte mutasies ken nie; ons ken slegs veranderinge van 'n kwantitatiewe of meer of minder patologiese aard" (Stoker 1926:41). Bykans 'n halwe eeu later skryf een van die prominente genetici van ons eeu, Th. Dobzhansky (1968:28), pertinent: "Mutation alone, uncontrolled by natural selection, could only result in degeneration, decay and extinction".

Wanneer Stoker met alle skerpte die verwarring tussen 'ooreenkoms' en 'afstamming' uitlig, bied hy nóg ' $n$ insig aan ons wat die toets van die tyd kon deurstaan. Met betrekking tot al die vermeende bewyse wat op grond van ooreenkomste opgestapel word, stel Stoker (1926:30) dat dieselfde logiese grondfout deurgaans aanwesig is: "Gelykheid (liewers gelykagtigheid - Aelınlichkeit) is 'n teken van genealogiese (= afstammings) verwantskap". Op verskeie verdere plekke word by herhaling van hierdie argument gebruik gemaak. Sowel Woods as Johannsen word ook instemmend ter ondersteuning van hierdie insig aangehaal (Stoker, 1926:32, vgl. 34). Stoker beklemtoon pertinent: nie "alleen op die ooreenkomste" nie, "maar veral op die verskille moet die oog gerig word" (Stoker, 1926:34). Vervolgens sluit Stoker aan by die totaliteitsopvatting van Hans Driesch se vitalistiese biologie en vermeld hy ook die opmerking van Johannsen wat stel dat "graduele evolusie" iets is wat "onbekend" is en dat "alle genotipiese ontwikkeling (mutasies) wat bekend" is "met spronge" geskied.

2 Hicrby moet ons in gedagtc hou dat dic neo-Danwinisme staan en val mct dic kombinasic van mutasic en natuurlike selcksic. 
Hierdie insig, naamlik dat uit ooreenkoms nie tot afstamming gekonkludeer kan word nie, word ook effektief deur Stoker (1926:37) aangewend om die onhoudbaarheid van homoloë organe as grond vir vermeende afstamming uit te wys.

Sistematies gesien, handel die verhouding tussen ooreenkomste en verskille oor die fundamentele aard van die mens se logies-analitiese vermoë. Analise berus tewens op die twee bene van identifisering en onderskeiding. Die merkwaardige van hierdie twee geledinge van analise is daarin geleë dat albei mekaar wederkerig veronderstel en impliseer. Dit beteken dat slegs geïdentifiseer kan word deur te onderskei en omgekeerd; daarom veronderstel elke analitiese aktiwiteit 'n (méér-as-logiese) verskeidenheid in die skepping.

Sodra ons egter verder besin oor die verband tussen identifisering en onderskeiding, moet ons uitkom by die aard van ooreenkomste en verskille. Identifisering en onderskeiding is immers slegs moontlik danksy/op die basis van ooreenkomste en verskille; daarom is dit onsinnig om byvoorbeeld te beweer dat twee mense absoluut verskil. Die implikasie sou wees dat daar eintlik slegs verskille tussen dergelike twee mense bestaan en geen enkele ooreenkoms nie. Aangesien albei egter mense is, bestaan daar in hul mens-wees steeds 'n fundamentele ooreenkoms wat in die konstatering van die verskille steeds veronderstel is.

Juis met betrekking tot die evolusieteorie - wat geneig is om die omgekeerde te doen deur alle klem op ooreenkomste te plaas - moet ons 'n soortgelyke kanttekening maak: die pretensie bestaan dat daar eintlik - as gevolg van die ooreenkomste - geén verskille bestaan nie en dat ons derhalwe eintlik met dieselfde entiteit te make het. Met ander woorde, vanuit die aanwesigheid van ooreenkomste word (met negasie van die verskille) tot identiteit gekonkludeer. Omdat ooreenkomste egter altyd verskille veronderstel en impliseer, is hierdie konklusie niks anders nie as ' $n$ sprong-redenasie. ${ }^{3}$

Die volgende belangrike - steeds steekhoudende - perspektief wat Stoker aan die orde stel, is sy besware teen die bekende argument van Häckel, naamlik dat die ontwikkelingsgang wat die individuele organisme van geboorte tot volwassenheid deurloop (ontogenese) ' $n$ herhaling/weerspieëling is van die stamhistoriese

3 Terloops kan ons daarop wys dat dic twee geledinge van analisc, te wete identifisering en onderskeiding, binne die modale struktuur van dic logies-analiticse werklikheidsaspek dic samehang met die getalsaspek tot openbaring bring aangesien dit fundamentecl berus op dic aard van 'n logies-analitiese eenheid en menigvuldigheid. Hicrdic getalsanalogic toon sig tewens aan die normsy van die logicse aspek in die gedaante van dic fundamentele logiese norme van identiteit en teëspraak - twee norme wat op hul beurt weer saamhang met die verdiepte betekenis van dic beginsel van die uitgeslote derde (vgl. hierby Strauss, 1991). 
wordingsgeskiedenis (filogenese). Dit staan bekend as die sogenaamde biogenetiese grondwet van Häckel: ontogenese is 'n rekapitulasie van die filogenese.

Jacob von Uexküll (1973) gaan skerp krities op hierdie vermeende wet van Häckel in wanneer hy in hoofstuk 6 van sy gemelde geskrif Theoretische Biologie oor die ontstaan van lewende wesens skryf. Hy omskryf hierdie wet as dié bewering wat stel dat 'n lewende entiteit in sy individuele ontwikkeling die ontwikkelingsgeskiedenis van sy voorvaders in 'n verkorte vorm deurloop (Von Uexküll, $1920 ; 1973: 219)$. Die belangrikste beswaar wat von Uexküll in hierdie verband teen die aansprake van die biogenetiese grondwet opper, is dat dit op 'n sirkelredenering berus. As gevolg van die feit dat ons nie presies weet hoe die 'voorvader-geskiedenis' daar uitsien nie, word hierdie vakuum opgevul deur afleidings te maak uit die individuele ontwikkelingsgeskiedenis. ${ }^{4}$ Stoker (1926:40) sluit hierby aan met sy opmerking:

... die biogenetiese grondwet kan eers bewys word, nadat die filogenese bewys is, terwyl gewoonlik die teenoorgestelde en metodologies ontoelaatbare weg gevoly is, om uit die ontogenese die filogenese te bewys, - hicr word die kar voor die perd gespan.

In hierdie verband hoef slegs gekyk te word na die uitvoerige artikel van die bioloog P. Overhage enkele dekades later oor die onhoudbaarheid van die 'biogenetiese grondwet' (vgl. Overhage, 1959).

Met dieselfde skerpte wys Stoker op die onhoudbaarheid van die argumentasie betreffende sogenaande mudimentêre organe. Om tewens 'n orgaan as 'rudimentêr' te tipeer, "moet eers bewys word dat dit rudimentêr is, dat dit nou nutteloos is en dat dit van vroeëre soorte geërf is" (Stoker, 1926:42).

Wat my opval in die uiteensetting, is dat Stoker duidelik so vroeg as 1926 reeds 'n besef gehad het van verskillende fasette van 'wetmatigheid'. In sy kritiek op die 'kreatiewe evolusie' bring hy 'n onderskeiding tussen die 'lewensbeginsel' wat 'n "wetmatigheid van hoër orde as die van fisikogemiese wetmatighede" verteenwoordig (Stoker, 1926:56). Weliswaar verbind hy hierdie onderskeiding aan die bydrae van dic vitalisme as biologiese standpuntinname en dit verklaar waarom hy enkele bladsye verder in vitalistiese trant van 'n '/ewensdrang' praat (Stoker, 1926:59). Laasgenoemde onderskei hy nogtans streng van die 'evolusiedrang'.

4 "Da man dic Geschichte der Ahnen gar nicht kennt. wurde sic ihrerseits aus der Entwicklung des Einzelwesens abgeleitet. und so wurden sic durch einen Zirkelsehluß bewiesen" (Von Uexküll. 1920, 1973:218). 
Sistematies gesien, is die term wetmatigheid natuurlik nie toereikend nie. In hierdie opsig het ook Dooyeweerd later aan hierdie ontoereikende uitdrukking bly vashou. Tydens die eerste tentamen wat ek in 1970 by prof. Henk Van Riessen afgelê het (as deel van my Doktoraalstudie aan die Vrije Universiteit), het hy my eie gebruik van die tern wetmattg bevraagteken en verduidelik dat slégs dit wat aan die wet onderworpe is wet-mátig kan wees. Slegs dít wat die máát van die wet besit, kan wetmatig genoem word. Die wet sélf is maat-gewend en kan gevolglik nooit die maat van die wet besit nie. Anders gestel: slegs iets wat aan die wet onderworpe is, kan die eienskap wetmatigheid besit. ${ }^{5}$

Wanneer Stoker die resultate van die beskikbare gegewens later in sy artikel opsom, sluit hy 'n merkwaardige gesigspunt in. Hy wys naamlik op die konstantheid wat nie ontken kan word nie:

Daar is ' $n$ beginsel van konstantheid, stabiliteit, variasiebreedte, of hoe u dit ook genoem sou wil hê. Hierdie beginsel manifesteer hom so duidelik in die eksperimente, dat dit onwetenskaplik sou wees, hom gewoonweg te negeer. Die duidelikheid laat so min te wense oor, dat ' $\mathrm{n}$ onbevooroordeelde bioloog dit naas die beginsel van variasie een van sy hoofbeginsels moet maak, waarop hy sy beskouinge gaan grond (Stoker, 1926:47).

In sy Slotwoord kom Stoker hierop terug wanneer hy opmerk dat ons die toekoms van die biologie sal moet afwag om te sien of die "polifiletiese desendensie" sal seëvier en of die "meer gematigde en wetenskaplik aan ons kennis van vandag aangepaste konstanteteorie weer in eer sal kom" (Stoker, 1926:61-62). Waar hy aan die einde van sy artikel kortliks terugkom op die "kreatiewe ewolusie" van genl. J.C. Smuts, sluit hy positief aan by die uitspraak van Bavinck (in sy geskrif: Pro en contra, evolutie, p. 38) wat skryf: "Er is alleen een worden, indien en omdat er een zijn is" (vgl. Stoker, 1926:65). Stoker se beswaar is juis dat Sinuts die 'syn' aan die 'worde' opoffer.

Die algemene grondprobleem waaroor dit hier gaan, is die verhouding tussen konstantheid en verandering (dinamiek). Die merkwaardige van Stoker se appèl op hierdie samehang is dat hy nie kies ten gunste van enigeen van hierdie twee nie. Hy beklemtoon juis die onverbreeklike samehang tusen albei en meen dat die fout wat Smuts maak juis daarin geleë is dat hy die één beklemtoon ten koste van die ander. In ' $n$ bepaalde sin het hy hiermee aansluiting gevind by ' $n$ grondprobleem van die kennisleer wat reeds deur Plato met alle skerpte raakgesien is. Plato het naamlik reeds besef dat indien alles volledig oorgegee was aan 'n

5 Vollenhoven se onderskeidinge - tussen dic universele wet, die universele kant van dinge en dic individucel-wecs van dinge - cerbiedig hierdic insig en bring ons derhalwe op hicrdie punt verder. 
immer-vloeiende stroom van wording en verandering, daar geen houvas vir enige kennisvorming daarvan sou wees nie. Gevolglik het hy eenvoudig sy ankerplek probeer vind in die verneende bo-sinnelike 'wese' van die dinge wat ontrokke is aan alle verandering. Hierdie insig is eers veel later van 'n natuurwetenskaplike basis voorsien toe Gallilei ingesien het dat die kontinuitteit van beweging oorspronklik is en nie afhanklik is van 'n oorsaak van die beweging nie. Teenoor die Aristoteliaanse opvatting - wat 'n oorsaak van beweging postuleer - stel Gallilei se traagheidswet dat 'n liggaam eenvoudig sy beweging konstant sal kontinueer tensy iets daarop inwerk (soos 'n krag of wrywing). Die enigste sinvolle vraag wat gevra kan word, is na die oorsaak van die verandering van beweging. Anders gestel: alle verandering en dinamiek kan alleen vasgestel word op die basis van konstansie

Stoker het later in sy filosofiese ontwikkeling steeds 'n besondere waarde toegeken aan die dinamiese trek van die werklikheid. Alles wat "dinamiek, krag of energie besit" is vir Stoker (1933:22) "werklik". Uiteindelik onderskei hy tussen verskillende dimensies van die skepping, met name die dimensies van modaliteite, van individuele en sosiale strukture, van gebeurtenisse en van waardes. Die 'vaste bepaaldheid' van die werklikheid kom tot openbaring in die eerste twee dimensies terwyl die 'dinamiese bepaaldheid' deur die kosmiese dimensie van gebeurtenisse aan ons getoon word (vgl. Stoker, 1961:36 e.v.; 1964:16 e.v.).

Indien ons op hierdie punt 'n vergelyking tussen die denke van Stoker en Dooyeweerd sou tref, is dit opvallend dat Dooyeweerd op 'n ander manier die problematiek van konstansie en dinamiek gehanteer het. In sy Engelse geskrifte lees ons wel dikwels van invariant structures maar selde van constant structures. Met betrekking tot die aard van norme sal hy wel die uitdrukking 'bo-individueel' of 'bo-willekeurig' gebruik, maar ook in hierdie verband lees ons geensins van die konstantheid (of: konstansie) van beginsels nie.

Die terme 'krag', 'energie' en 'werking' wat Stoker verkieslik ter aanduiding van die 'dinamiese trek' van die werklikheid gebruik, appelleer inderdaad alınal op die fisiese aspek van die werklikheid. Indien ons die sin-kern van die fisiese aspek aandui met die tenne-paar energie-werking, is dit duidelik dat die fisiese aspek ook die tuiste vorm van die kousaliteitsrelasie, dit wil sê die relasie tussen oorsaak en gevolg. Die 'werking' van 'energie' het immers steeds bepaalde 'veranderinge' tot/as 'gevolg'.

Die sin van die fisiese aspek vorm egter ook die basis van die uitdrukking 'van krag wees', dit wil sê die gelding van iets. Uit die neo-Kantiaanse Badense skool tref ons tewens die veelvuldige gebruik van die uitdrukking 'algemeen-geldig' (resp. 'universeel-geldig') aan (vgl. die filosofie van Rickert en Windelband). Dooyeweerd sluit onkrities by hierdie erfenis aan in sy eie veelvuldige spreke van universal validity. Hoewel Hommes (1972) in sy geskrif oor die elementêre 
grondbegrippe van die regswetenskap reeds ingesien het dat die term 'gelding' op die oorspronklike sin van die fisiese aspek appelleer (van krag wees), het hyself nog gemeen dat sowel 'konstansie' as 'dinamiek' deel uitmaak van (en tuishoort binne) die fisiese aspek.

Veral met betrekking tot die aard van heginsels is dit problematies om die uitdrukking 'universeel-geldig' te gebruik. Na sy aard is 'n beginsel immers 'n universele, konstante begin-punt (vgl. Strauss, 1980:65). Danksy of uit hoofde van die universaliteit van 'n beginsel is dit juis nie vanself 'van krag' of 'geldig' nie - soos ten onregte deur die tradisionele natuurregsleer geglo is. ${ }^{6}$ 'n Beginsel (begin-sel) bied slegs die begin-punt vir menslike optrede. Die mens moet in die verlengde van hierdie beginpunt optree en wel deur die nornatiewe appèl daarvan in konkrete historiese omstandighede tot gelding te bring, van krag te maak of positiewe vorm daaraan te gee (te positiveer). ${ }^{7}$

In soverre ' $\mathrm{n}$ beginsel geldig is, is dit nie meer ongespesifiseerd universeel nie en in soverre ' $n$ beginsel nog ongekwalifiseerd universeel is, kan dit nie 'van krag' ('geldig') wees nie.

Hoewel ons gesien het dat Stoker aanvanklik - in sy skerp en nog steeds toepaslike kritiek op die (neo-)Darwinisme - 'n gesonde intuïsie ten opsigte van die verhouding tussen konstansie en dinamiek (verandering) geopenbaar het, het hy in sy ontologiese onderskeidinge nie ruimte gelaat vir 'n korrekte 'plasing' van die term 'konstansie' nie omdat hy die kinematiese aspek in sy dimensie van modaliteite nie erken het nie. Die ironie is egter dat Dooyeweerd, wat wel later in sy ontwikkelingsgang die kinematiese aspek onderskei en dit selfs doen met 'n eksplisiete beroep op Gallilei se wet van inersie (vgl. Dooyeweerd, 1955:99), nooit besef het dat die modale tuiste van die tern 'konstansie' slegs in die kinematiese aspek te vind is nie. 8

6 Volgens die natuurregslcer bestaan daar immers (rede-)regsreëls wat vir alle tye en plekkc vansclf geldig is.

7 Dic wyse waarop Stoker in sy Beginsels en metodes (1961) 'n ontleding van 'bcginscls gee, skenk ongelukkig nic aandag aan hicrdic fundamentele omskrywing van beginsels as universcle konstante vertrekpunte wat op menslike iussenkoms aangewese is om gepositiveer te word nic.

8 Dic orde van konstansie aan dic wetsy' van dic kinematicse aspek word weerspicël deur dic snelheid (c) van lig (in ' $n$ vakuum) in Einstcin se relatiwitcitstcoric - wat konstant is. Allc beweging is relaticf met betrekking tot hierdic orde van konstansic - wat beteken dat dic naamgewing relatiwiteitsteorie 'n mislcidende aanduiding is: Einstein se tcoric is in dic eerste plck 'n tcoric van konstansic! 
Ek is oortuig dat sowel Stoker as Dooyeweerd op hierdie punt verder sou gekom het indien hulle besef het dat die terme 'konstansie' en 'dinamiek' inderdaad bloot appelleer op die funderingsverhouding tussen die kinematiese en die fisiese aspekte van die werklikheid. Die onvennydelike en onherroeplike (fisiese) modale tuiste van terme soos krag, energie en dinamiek sou waarskynlik ook kon help om Stoker anders te laat nadink oor die dimensie van gebeurtenisse wat hy onderskei. Bloot die erkenning van die onvermydelike funksie wat elke entiteit ook in die fisiese aspek van die werklikheid besit, sou reeds voldoende ruimte bied om rekenskap van die dinamiese aard van werklike dinge in die skepping te gee.

Nogtans beskou ek dit as een van die mees standhoudende winspunte wat opgesluit lê in Stoker se artikel uit 1926 oor die moderne desendensieleer dat hy daarin so skerp gewys het op die noodsaaklike erkenning van konstansie as basis vir alle veranderlikheid. Die trefkrag van die eerste aanvoeling wat hy in hierdie verband geopenbaar het, transendeer na my mening nog steeds in trefkrag sowel sy eie latere bydrae as Dooyeweerd se bydraes in verband met hierdie problematiek.

Om tot hierdie positiewe waardering te kon kom, is egter 'n werkwyse gevolg wat skynbaar lynreg indruis teen die werkwyse wat Stoker in sy 1926-artikel gevolg het. Hy het in hierdie artikel deurgaans juis (tereg) daarop klem gelê dat die ooreenkomssoeke van evolusioniste maklik tot ongegronde 'identiteitskonklusies' aanleiding kan gee. Onbewus beweeg Stoker hiermee in dieselfde veiliger vaarwater as die Switserse bioloog Adolf Portmann wat met navorsing oor die verskille tussen mens en dier verstommende (anti-Darwinistiese) perspektiewe op die uniekheid van die mens geopen het - vgl. Portman (1969). (Vergelyk ook sy onderskeiding tussen die twee ontogenetiese ontwikkelingstipes wat ' $n$ mens by die hoër ontwikkelde gewerwelde diere kan onderskei, te wete Nesthocker en Nestflüchter.)

In hierdie bydrae was ek 'ongehoorsaam' aan hierdie 'eis' van Stoker, want my mikpunt was juis om te kyk wátter insigte van hom uit die jaar 1926 (op 'ooreenstemmende wyse') vandag nog steeds stand hou!

\section{Bronne}

DOBZHANSKY, Th. 1968. The Biology of Ultimate Concern. New York: The New American Library.

DOOYEWEERD, H. 1955. A New Critique of Theoretical Thought. Vol. II. Philadelphia Presbyterian Publishing Company.

HOMMES, H.J. 1972. De elementaire grondbegrippen der rechtswetenschap. Deventer Kluver.

OVERHAGE, P. 1959. Keimesgeshichte und Stamme. (In Haas, Adolf, samest. Die stammesgeschichtliche Werden der Organismen und des Menschen, Vol. I. Wenen : Herder. p. 166-197.) 
PORTMAN, A. 1969. Biologische Fragmente zu einer Lehre von Menschen. 3e Druk. Basel : Schwabe \& Co Verlag.

STOKER, H.G. 1926. Die desendensieleer in die moderne Biologie. ( $/$ " "Skrif en die Natuurwetenskappe", uitgegee deur die 'Kristelike Unie' as nommer 1 van die Serie: "Heilige Skrif en Wetenskap".)

STOKER, H.G. 1933. Die Wysbegeerte van die Skeppingsidee. Pretoria : J.H. de Bussy.

STOKER, H.G. 1964. Die kosmiese dimensie van gebeurtenisse. Philosophia Reformata, 29 (1\& 2):1-67.

STOKER, H.G. 1961. Beginsels en metodes in die wetenskap. Potchefstroom : Pro Rege Pers.

STRAUSS, D.F.M. 1980: Inleiding tot die Kosmologie. Bloemfontein : VCHO.

STRAUSS, D.F.M. 1991. The Ontological Status of the Principle of the Excluded Middle Philosophia Mathematica, 6(1):73-90.

VON UEXKÜLL, J. 1973. Theoretische Biologie. (1920, 19282). Frankfurt am Main Surhkamp. 